\title{
KUALITAS SEKOLAH DASAR ISLAM TERPADU DI JAWA BARAT (SDIT NURUL FIKRI DAN SDIT UMMUL QURO)
}

\author{
Muhammad Fahri \\ Fakultas Agama Islam, Universitas Ibn Khaldun Bogor \\ fahri@fai.uika-bogor.ac.id \\ Salati Asmahasanah \\ Fakultas Agama Islam, Universitas Ibn Khaldun Bogor \\ salati@fai.uika-bogor.ac.id
}

\begin{abstract}
This research is aimed to describe profile of Islamic elementary education and to know the quality assurance implemented in qualified schools in West Java, Indonesia. The method used is qualitative. The research found that JSIT (Jaringan Sekolah Islam Terpadu) has 11 own quality assurances implemented in their accreditation and it improves 10 Islamic characters. Beside according to JSIT quality assurance and its characters, SDIT Nurul Fikri improves character of SMART (Sholeh, Muslih, cerdAs, mandiRi and Terampil). SDIT Ummul Quro strengthens characters; humble, clean and neat, pray, birrul walidain, discipline, honest, reading and memorizing Qur'an, and learner. The results of these studies can be information, consideration and implementation for education practitioners, stakeholders, researchers and the public in general.
\end{abstract}

Key Words: Elementary Education; Quaity; SDIT

\section{ABSTRAK}

Penelitian ini bertujuan untuk mendeskripsikan profil pendidikan dasar Islam dan untuk mengetahui jaminan mutu yang dilakukan di sekolah-sekolah berkualitas di Jawa Barat, Indonesia. Metode yang digunakan adalah kualitatif. Penelitian tersebut menemukan bahwa JSIT (Jaringan Pendidikan Islam Terpadu) memiliki 11 jaminan kualitas yang diterapkan dalam akreditasi mereka dan meningkatkan 10 karakter Islam. Selain sesuai dengan jaminan mutu dan karakter JSIT, SDIT Nurul Fikri meningkatkan karakter SMART (Sholeh, Muslih, cerdAs, mandiRi dan Terampil). SDIT Ummul Quro memperkuat karakter; rendah hati, bersih dan rapi, shalat, birrul walidain, disiplin, jujur, membaca dan menghafal Al Qur'an, dan pembelajar. Hasil penelitian tersebut dapat digunakan sebagai informasi, pertimbangan maupun implementasi bagi para praktisi pendidikan, peneliti maupun masyarakat secara umum.

Kata Kunci: Pendidikan Dasar; Kualitas; SDIT

\section{A. Pendahuluan}

Dunia pendidikan di Indonesia memiliki dinamika yang beragam khususnya bidang pendidikan dasar di tingkat SD sederajat. Keberagaman itu meliputi 
perkembangan dalam manajemen pengelolaan kegiatan pembelajaran, kurikulum, SDM, biaya, sarana prasarana dan lain sebagainya. Lembaga pendidikan seolah-olah berlomba-lomba untuk menjadikan sekolahnya unggulan dan diminati masyarakat. Hal ini tidak terlepas dari fungsi pendidikan itu sendiri sesuai dengan Pasal 3 UU No. 20/2003 menyatakan bahwa pendidikan nasional berfungsi mengembangkan kemampuan dan membentuk watak serta peradaban bangsa yang bermartabat dalam rangka mencerdaskan kehidupan bangsa. Dalam rumusan pasal 3 UU No. 20/2003 ini terkandung empat fungsi yang harus diaktualisasikan oleh pendidikan, yaitu: fungsi mengembangkan kemampuan peserta didik; fungsi membentuk watak bangsa yang bermartabat; fungsi mengembangkan peradaban bangsa yang bermartabat, dan fungsi mencerdaskan kehidupan bangsa.

Selain itu, jika kita lihat dari diagram jumlah sekolah yang tersebar di pulau Jawa khususnya Jawa Barat ternyata SDIT lebih banyak dibanding jenis sekolah lain. Hal ini terlihat dari diagram di bawah ini:

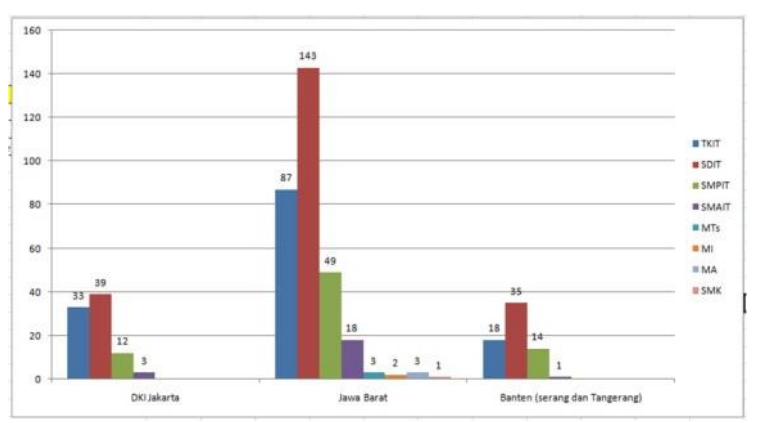

Diagram Sekolah di DKI, JABAR, BANTEN (source:sdit-irsyadulibad.blogspot.com 2013)

Hal ini membuktikan bahwa minat masyarakat terhadap sekolah dasar swasta yang berbasis Islam terpadu cukup tinggi. Sehubungan dengan hal tersebut menjadi pendukung dan motivasi untuk meneliti lembaga pendidikan dasar berbasis Islam yang unggulan di Jawa Barat. Fokus objek penelitian ini adalah Sekolah Dasar Islam Terpadu (SDIT) di bawah naungan Jaringan Sekolah Islam Terpadu (JSIT). Alasannya, dikarenakan hampir di setiap daerah SDIT dianggap sebagai sekolah unggul yang berprestasi baik akademik dan non akademik. Berawal dari lima satuan sekolah dasar yang berdiri pada 1993 di wilayah Jabodetabek, Sekolah Islam Terpadu (SIT) telah berkembang pesat di seluruh Indonesia.

Musyawarah Nasional IV (Munas) JSIT Indonesia yang 
berlangsung di Hotel Lombok Raya, Kota Mataram, Nusa Tenggara Barat pada Kamis-Ahad, 27-30 Juli 2017 yang salah satunya keputusannya adalah menghasilkan kepengurusan baru untuk periode 4 tahun ke depan, 2017-2021 yang dipimpin oleh Mohammad Zahri, M.Pd. Terdapat lima hal yang disampaikan; Pertama, ucapan terima kasih atas kepercayaan dan amanah sebagai ketua JSIT Indonesia yang baru. Kedua, prioritas program JSIT Indonesia periode 2017-2021 adalah terwujudnya SIT yang berprestasi. Siswanya berprestasi. Guru dan tenaga kependidikan juga berprestasi. Tentu saja, sekolah berprestasi juga. Prestasi di banyak bidang baik bidang akademik maupun nonakademik. Pada bidang akademik, SIT berprestasi dalam bidang teknologi, bahasa, karya tulis ilmiah, pramuka, al Quran mulai satuan pendidikan TKIT/RA, SDIT/MI, SMPIT/MTs hingga SMAIT/MA. Pada bidang nonakademik, SIT berprestasi dalam bidang pembinaan karakter akhlak mulia, sekolah sehat, sekolah berwawasan wiyatamandala, sekolah ramah anak, atau sebutan sekolah berprestasi lainnya. Kepala sekolahnya berprestasi. Bahkan gurunya pun berprestasi. SIT berprestasi karena mampu mewujudkan sebagai SIT yang efektif dan bermutu sebagaimana visi JSIT Indonesia sebagai Pusat Penggerak dan Pemberdaya sekolah Islam terpadu menuju efektif dan bermutu. Ketiga, agar SIT berprestasi, diperlukan strategi yang tepat. Strategi utama untuk mewujudkan prestasi tersebut yaitu meningkatkan kualitas kepala sekolah dan guru, kemudian melakukan modernisasi pengelolaan sekolah, dan memperluas kerjasama yang efektif. Tanpa strategi yang tepat, kita akan kesulitan menghasilkan SIT berprestasi. Dalam era teknologi informasi ini, kekuatan networking antar anggota SIT menjadi salah satu katalisator peningkatan mutu sekolah-sekolah Islam terpadu. Keempat, khusus bagi SIT yang sudah berusia lebih dari 15 tahun alias melebihi usia ulang tahun JSIT Indonesia yang pada 30 Juli 2017 ini berusia 14 tahun, perlu segera melakukan inovasi secara massif agar tetap tumbuh dan berkembang menjadi sekolah pilihan utama masyarakat. SIT-SIT tersebut segera melakukan lisensi oleh JSIT Indonesia. Hal ini penting agar SIT- 
SIT tersebut dapat menjadi sekolah model bagi yang lainnya. Kelima, organisasi SIT perlu melakukan pemberdayaan dan pengembangan peran setingkat regional dan wilayah agar JSIT Indonesia semakin mandiri dan cepat merespons perkembangan dunia pendidikan terkini. (https://jsitindonesia.com/2017/08/02/ketua-jsitbaru-menyapa-kita/ diakses tanggal 4 september 9:50)

\section{B. Landasan Teori}

Pendidikan Islam adalah pendidikan yang bertujuan untuk membentuk pribadi Muslim seutuhnya atau holistik, mengembangkan seluruh potensi manusia baik yang berbentuk jasmaniah maupun rohaniah, menumbuhsuburkan hubungan harmonis setiap pribadi dengan Allah, manusia dan alam semesta. Kedudukan pendidikan Islam di Indonesia adalah bagian integral dari pendidikan nasional. Karena pendidikan Islam adalah sub-sistem dari sistem pendidikan nasional. Dapat dilihat dari tiga aspek, pendidikan Islam sebagai mata pelajaran, sebagai lembaga dan sebagai nilai.
Kebijakan pendidikan adalah salah satu kebijakan negara dan berpijak pada legalitas hukum yang diatur secara hirarkis dari yang tertinggi hingga yang terendah. Pancasila sebagai kedudukan dasar negara Indonesia, sedangkan UUD 1945 dan GBHN masing-masing berkedudukan sebagai landasan konstitusional dan operasional dari sistem pendidikan nasional. (Anwar, 2014: 488)

Maka dari itu makna dari pendidikan sejatinya bukan hanya sekedar mengajarkan ilmu pengetahuan tapi juga memberikan perubahan perilaku di segala aspek kehidupan yang seimbang antara di dunia dan akhirat. Sehingga kita jumpai saat ini pendidikan berbasis Islam mulai berkembang pesat di masyarakat. Adapun definisi pendidikan Islam adalah suatu proses yang melatih perasaan murid-murid dengan cara sedemikian rupa sehingga dalam sikap hidup, tindakan, keputusan dan pendekatan mereka terhadap segala jenis pengetahuan mereka yang dipengaruhi dengan nilai-nilai spiritual dan sangat sadar akan nilainilai Islam. 
Strategi pendidikan untuk meningkatkan kualitas murid atau peserta didik terdiri dari dua model, yaitu strategi pendidikan yang bersifat makro yang terdiri dari tiga komponen utama, yaitu pertama, tujuan pendidikan Islam yang mencakup kesempurnaan agama. Kedua dasardasar pokok pendidikan Islam yang menjadi landasan kurikulum terdiri dari delapan aspek; keutuhan, keterpaduan, kesinambungan, keaslian, bersifat imiah, bersifat praktikal, kesetiakawanan, dan keterbukaan. Ketiga, prioritas dalam tindakan yang meliputi penyerapan semua anak-anak yang mencapai usia sekolah, kepelbagaian jalur pengembangan, meninjau kembali materi dan metode pendidikan, pengukuhan pendidikan agama, administrasi dan perencanaan, dan kerjasama regional dan antar negara di dalam dunia Islam. Sedangkan strategi yang bersifat mikro hanya terdiri dari satu komponen, yaitu tazkiyah an-nafs (pembersihan jiwa). Tazkiyah bertujuan untuk membentuk tingkah laku yang dapat menyeimbangkan roh, akal dan badan seseorang. (Dahlan, R, 2015: 70)
Dalam

implementasinya kurikulum pendidikan dasar berbasis Islam disusun sebagai pencapaian tujuan pendidikan nasional dengan memperhatikan tahap perkembangan siswa dan kesesuaian lingkungan Agama, kebutuhan siswa, perkembangan ilmu pengetahuan dan teknologi. Menjadikan sekolah yang unggul dari berbagai aspek kehidupan adalah cita-cita suatu lembaga pendidikan.

Istilah sekolah unggul sebenarnya tidak dikenal dalam ilmu pendidikan. Semua sekolah bertujuan unggul, jika ingin menggunakan kata unggul dalam pendidikan Islam adalah sekolah yang yang dapat mencapai tujuan sekolah secara maksimal. Berdasarkan pengertian inilah maka tidak ada sekolah unggul dan tidak unggul; semua sekolah adalah sekolah unggul, hanya saja ada yang berhasil unggul ada yang tidak (Tafsir, 2013: 115)

Dalam Islam tidak terdapat sistem pendidikan yang baku, melainkan terdapat nilai-nilai moral dan etika yang seharusnya mewarnai sistem pendidikan tersebut. Berbagai komponen yang terdapat dalam suatu konsep pendidikan. Seperti pengertian pendidikan Islam yang 
akan menghantarkan kepada pemahaman yang benar sehingga pengamalan ajarannya pun benar. Komponen yang lain seperti tujuan, kurikulum, evaluasi dan lain sebagainya harus didasarkan pada nilai-nilai ajaran Islam. Hal inilah yang menjadi ciri khas yang membedakan antara pendidikan Islami dengan pendidikan yang tidak Islami. (Abdat, 2014: 17)

\section{Metode Penelitian}

Penelitian ini menggunakan penelitian kualitatif (Qualitative research). Penelitian kualitatif adalah suatu penelitian yang ditujukan untuk mendeskripsikan dan menganalisis fenomena, peristiwa, aktivitas sosial, sikap, kepercayaan, persepsi, pemikiran orang secara individual maupun kelompok (Sukmadinata, 2010: 60).

Metode pengumpulan dan analisis data penelitian kualitatif bersifat interaktif, berlangsung dalam lingkaran yang tumpang tindih. Langkah-langkahnya disebut strategi pengumpulan dan analisis data, teknik yang digunakan fleksibel, tergantung pada strategi terdahulu yang digunakan dan data yang telah diperoleh (Sukmadinata, 2010:114).
Milles dan Huberman (dalam Sangit, 2011) mengemukakan bahwa pendekatan dalam analisis data kualitatif terdiri dari koleksi data, reduksi data, display data, dan verifikasi data yang dilakukan dalam bentuk interaktif dengan proses pengumpulan data sebagai suatu proses yang berlanjut, berulang, dan terus menerus hingga membentuk suatu siklus. Sebagaimana terlihat pada gambar di bawah ini:

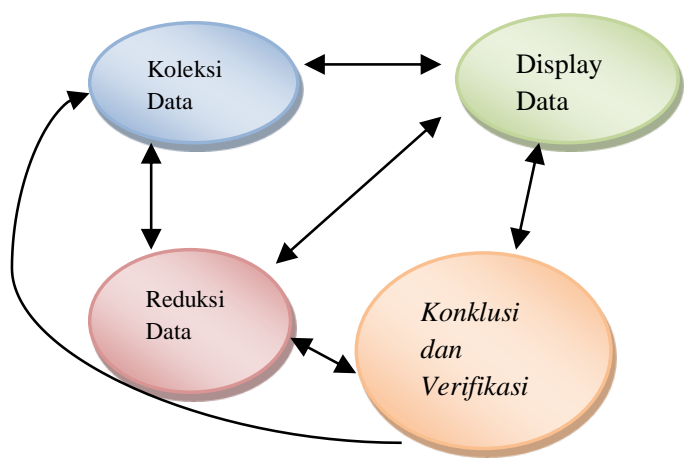

Gambar Analysis Data Kualitatif Sumber: Miles and Huberman

Penelitian yang dilakukan di dua sekolah dasar Islam yang berkualitas di bawah Jaringan Sekolah Islam Terpadu (JSIT) adalah Sekolah Dasar Islam Terpadu Nurul Fikri Depok, dan Sekolah Dasar Islam Terpadu Ummul Quro Bogor. 
D.Hasil Penelitian danPembahasan

1. Jaminan Mutu Sekolah Islam Terpadu (SIT)

Sekolah Islam Terpadu (SIT) menerapkan konsep Pendidikan Islam berbasis Al Qur'an dan As Sunnah. Istilah "terpadu" atau diintegrasikan sebagai titik kekuatan (taukid) Islam itu sendiri. Islam sebagai kesatuan, komprehensif dan terpadu atau syumuliyah bukan juziyah. Ini menjadi gerakan dakwah di bidang pendidikan sebagai pembela pemikiran sekuler dan dycotomy dalam dunia pendidikan. $\mathrm{Di}$ bidang kurikulum, SIT melakukan kurikulum terpadu, artinya semua mata pelajaran di sekolah terintegrasi dalam pandangan islam, tidak ada dycotomy atau sekularisasi. Oleh karena itu, kurikulum inti di SIT didasarkan pada kepercayaan kepada Allah SWT yang dinyatakan atau tersirat dalam Al Qur'an dan Hadits selain exemplifieing dari guru untuk membangun karakter siswa khususnya dalam ibadah (ubudiyah) dan karakter islam (akhlaqiyah). Di bidang metode pembelajaran, SIT mengoptimalkan aspek kognitif, afektif dan konatif satu berdasarkan pada pemecahan masalah dan kreativitas. Selain SIT pendidikan terpadu aqliyah, ruhiyah dan jasadiyah. Dengan ketiga aspek tersebut siswa dapat meningkatkan kecerdasan, kualitas iman kepada Allah dan memiliki tubuh yang sehat. Misi dan tujuan utama pembentukan SIT adalah mewujudkan sebuah sekolah yang secara efektif mengembangkan proses pendidikan yang dapat mendorong potensi siswa terhadap visi pembentukan generasi dan karakter 'taqwa'. Berdasarkan filosofi yang mengacu pada pesan pendidikan Islam sebagaimana dirangkum dalam AI Qur'an, sekolah Islam berikutnya bersatu memperkuat misi pendidikan yaitu:

1. Menyelesaikan tujuan pembelajaran yang ditetapkan oleh pemerintah dalam konteks kurikulum nasional;

2. Mengajar kemampuan membaca Alquran dengan standar tahsin dan tartil (membaca menurut hukum tajwid) dan kemampuan menghafal al-Qur'an (tahfidzul quran) dengan standar minimal dua juz masingmasing. tingkat unit pendidikan;

3. Memperkuat pembelajaran Islam, dengan memperkaya isi kurikulum yang mengarah pada pemahaman dasar ajaran Islam dan pembinaan fikrah, mauqif dan suluk islamiyah: 
4. Membangun karakter/muwashofat kepada peserta didik secara bertahap menuju terbentuknya generasi pemimpin cerdas dan taqwa. Tujuan pendidikan SIT adalah untuk membentuk 10 karakter utama bagi semua peserta didik (Alaydroes, dkk, 2014), yaitu:

a. Salimul Aqidah: meyakini Allah SWT sebagai pencipta, pemilik, pemelihara dan penguasa alam semesta dan menjauhkan diri dari segala fikiran, sikap dan perilaku bid'ah, khurafat dan syirik;

b. Shohihul ibadah; terbiasa dan gemar melaksanakan ibadah meliputi; shalat, shaum, tilawah qur'an, dzikir dan doa sesuai petunjuk Al Qur'an dan As Sunnah;

c. Matinul Khuluq: menampilkan perilaku yang santu, tertib, disiplin, sabar, gigih, dan pemberani dalam menghadapi permasalahan hidup sehari-hari

d. Qodirun ‘alal kasbi: mandiri dalam memenuhi kebutuhan hidupnya dan memiliki bekal yang cukup dalam pengetahuan, kecakapan dan keterampilan dalam usaha memenuhi

kebutuhan

nafkahnya;

e. Mutsaqoful Fikri: memiliki kemampuan berpikir yang kritis, logis, sistematis dan kreatif yang menjadikan dirinya berpengetahuan luas dan menguasai kompetensi akademik dengan sebaikbaiknya dan cermat serta cerdik dalam mengatasi segala masalah yang dihadapi;

f. Qowiyyul Jismi: memiliki badan dan jiwa yang sehat dan bugar, stamina dan daya tahan tubuh yang kuat, serta keterampilan beladiri yang berguna untuk dirinya dan orang lain;

g. Mujahadah Lin Nafsi: memiliki kesungguhan dan motivasi yang tinggi dalam mengejar presetasi sekolah;

h. Munadzom fi Syu'nihi: tertib dalam menata segala pekerjaan, tugas dan kewajiban; berani dalam mengambil resiko namun tetap cermat dan penuh perhitungan dalam melangkah;

i. Haristun alal Waqti: selalu memanfaatkan dan mengatur waktu dengan kegiatan yang bermanfaat; 
j. Nafiun Lighoirihi: peduli dan bermanfaat kepada sesama dan lingkungan serta memiliki kepekaan untuk membantu orang lain.

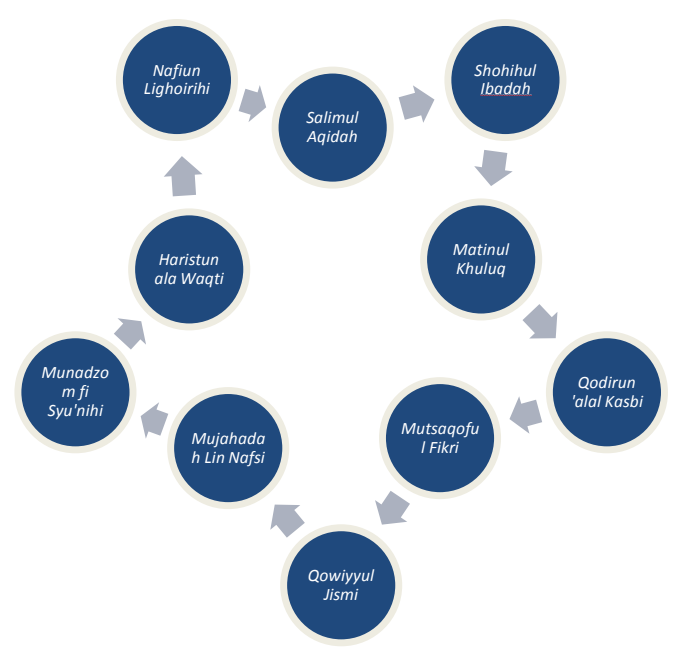

Gambar 10 Karakter SIT

Sekolah Islam terpadu selalu menjaga kualitas dengan selalu memperhatikan dan meningkatkan standar menjadi persyaratan kualitas dan akreditasi internal Jaringan Sekolah Islam Terintegrasi. Ada 11 standar kualitas yang dikembangkan oleh Integrated Islamic School Network, yaitu: Standar Pendidikan dan Personalia; Standar Fasilitas dan Prasarana; Standar Pembiayaan; Standar Kurikulum; Standar Manajemen; Standar Kerjasama; Standar Proses; Standar Penilaian; Standar Pelatihan; Standar
Pendidikan Agama Islam; dan Standar Kompetensi Lulusan.

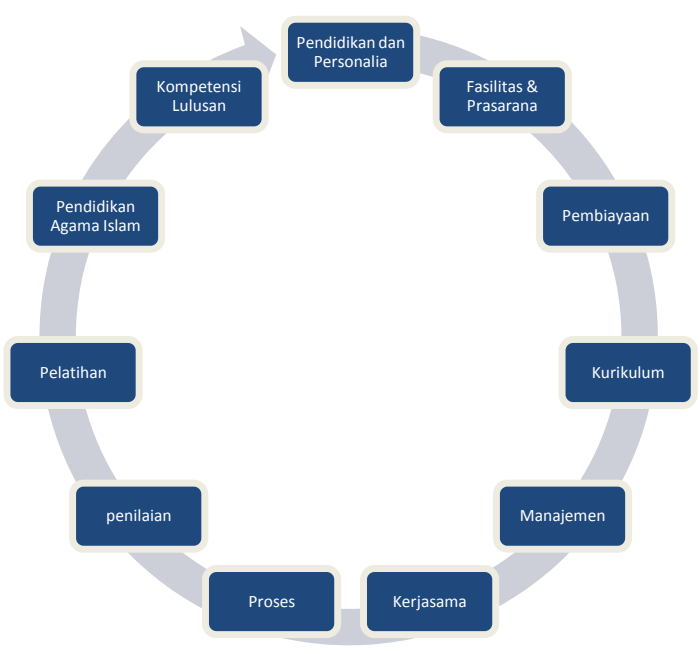

Gambar 11 Standar SIT

2. Profil dan Kualitas SDIT Nurul Fikri Depok

SDIT Nurul Fikri didirikan pada tahun 1993, dengan niat berdakwah dan semangat untuk memberikan perbaikan terhadap mutu pendidikan sekolah Islam pada saat itu. SDIT Nurul Fikri berpandangan bahwa sudah selayaknya sekolah-sekolah Islam dapat berkompetisi dengan sekolah lainnya dalam mencerdaskan anak bangsa, yang tentu saja bukan sekedar menonjolkan IQ, akan tetapi juga $E Q$ dan $S Q$. Berbekal keikhlasan dan kekuatan tekad, Alhamdulillah, konsep keterpaduan antara IPTEK dan IMTAQ yang digagas SDIT Nurul Fikri, sekarang sudah banyak diadopsi oleh institusi pendidikan 
Pendas : Jurnal IImiah Pendidikan Dasar, ISSN Cetak : 2477-2143 ISSN Online : 2548-6950 Volume II Nomor 2, Desember 2017

lainnya di berbagai wilayah di Indonesia. Sebagai sekolah Islam terpadu, Islamisasi pembelajaran menjadi spirit dalam aktifitas belajar dan mengajar di SDIT Nurul Fikri. Sistem fullday school yang diterapkan di sekolah, menjadikan budayabudaya Islami lebih mudah untuk ditanamkan ke dalam diri anak didik, mulai pagi hari pukul 07.15 WIB sampai sore hari selepas shalat ashar.

SDIT Nurul Fikri memiliki visi yaitu; Menjadi lembaga pendidikan sekolah dasar terbaik dalam mendidik siswanya agar berakhlak mulia, berpengetahuan, dan terampil dalam hidup sesuai pertumbuhan dan perkembangan usianya. Sementara misi SDIT Nurul Fikri adalah: Menyelenggarakan pendidikan dasar umum dan Islam yang mampu membentuk karakter, sikap, dan perilaku sesuai tuntunan anak dalam Islam serta memberikan bekalan pengetahuan dan keterampilan untuk tumbuh dan berkembang secara optimal.

Sekolah Islam terpadu Nurul Fikri mengidentifikasi karakter yang akan dikembangkan adalah terangkum dalam dimensi Sholeh, Muslih, cerdAs, mandiRi dan
Terampil disederhanakan dengan akronim SMART NF. Deskripsi masisng-masing dimensi SMART NF (Bidang Pendidikan: 2016: 3), adalah sebagai berikut:

1. Sholeh

Dimensi sholeh meliputi aspek pemventukan karakter individu siswa dalam kaitannya dengan ketaatan kepada Allah SWT dalam mengimplementasikan keyakinan akan pengawasan Allah SWT. Dimensi sholeh juga dapat diartikan sebagai karakter yang terkait langsung dengan nilai religiuitas (keberagamaan). Sebagai lembaga pendidikan Islam, NF berkomitmen untuk menjadikan siswa yang taat beribadah dengan berlandaskan kepada aqidah ahlus sunnah.

2. Muslih

Dimensi muslih dalam akronim SMART melingkupi karakter kepemimpinan yang akan ditanamkan pada siswa-siswi SIT Nurul Fikri. Dengan tertanamnya dimensi Muslih pada peserta didik maka diharapkan lulusan SIT Nurul Fikri memiliki paradigma, prinsip, nilai dan keterampilan kepemimpinan. NF berkomitmen untuk membentuk siswa sebagai 
Pendas : Jurnal IImiah Pendidikan Dasar, ISSN Cetak : 2477-2143 ISSN Online : 2548-6950 Volume II Nomor 2, Desember 2017

pemimpin yang menjadi pelopor dan senantiasa peduli terhadap berbagai fenomena yang terjadi di masyaraka, bertanggung jawab, mencintai tanah air dan siap membangun komunikasi dengan siapapun untuk terwujudnya kerjasama dengan semua elemen bangsa.

\section{Cerdas}

Dimensi cerdas dalam akronim SMART diarahkan pada karakter yang ada dalam individu cerdas. NF berkomitmen untuk membentuk siswa menjadi proibadi yang memiliki keingintahuan yang tinggi senantiasa berfikir mendalam terhadap berbagai fenomena, terbuka terhadap gagasan dari orang lain untuk bersama-sama memberikan usulan penyelesaian masalah dengan terus menerus meningkatkan pengetahuan dan keterampilan yang dimiliki.

4. Mandiri

Dimensi karakter mandiri diarahkan pada pembentukan sikap kemandirian individu dalam menyelesaikan masalah yang dihadapi dalam keseharian. Kemandirian bagi seorang siswa adalah mutlak diperlukan, baik yang bersifat sikap mandiri (soft skill) maupun kemapuan melakukannya sendiri (hard skill). NF berkomitmen untuk membentuk pribadi siswa yang kratif dan memiliki jiwa enterpreneur dengan berani mengambil keputusan dan memperhitungkan resiko yang mungkin terjadi.

5. Terampil

Dimensi terampil lebih diarahkan kepada hardskill, berupa sikapsikap dan kemampuan yang dibutuhkan dalam menyelesaikan berbagai persoalan yang dihadapi. NF berkomitmen untuk membentuk siswa yang tangkas dan cekatan serta memiliki keterampilan berbahasa Indonesia maupun bahasa Asing memiliki pengetahuan serta keterampilan terhadap teknologi informasi serta memiliki kemampuan berolahraga dan berkesenian.

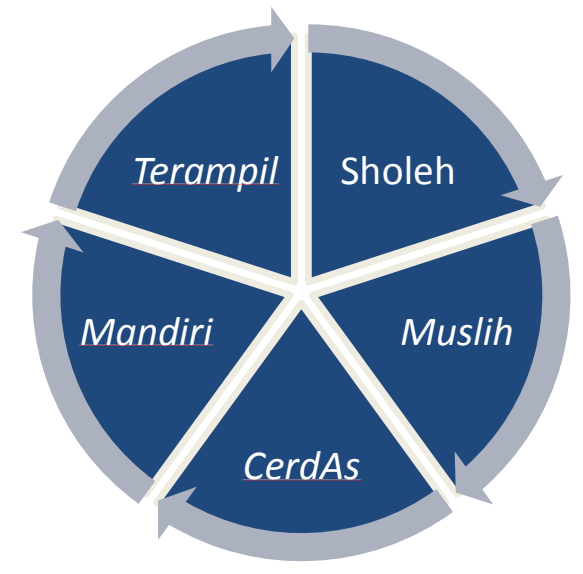

Gambar Karakter SDIT Nurul Fikri 
3. Profil dan Kualitas of SDIT Ummul Quro Bogor

Ummul Quro Bogor adalah sebuah institusi atau yayasan yang bergerak di bidang pendidikan dalam bentuk Sekolah Islam terpadu dari TK sampai SMA dan DGPQ (Pelatihan untuk Guru Al Quran). Berawal dari cita-cita luhur dua orang waqif, yaitu H. Muh. Nawir dan H. Mursyidin yang memiliki keinginan yang sama untuk membangun masjid kemudian mewujudkan cita-cita tersebut, Ustadz Drs. H. Dja'far Aziz (saat itu dia adalah pemimpin Panti Asuhan Darush-Sholihin) memfasilitasi dan menyampaikannya kepada Ustadz Ir. H. Suswono, MM (saat itu sebagai Kepala Yayasan Sholahuddin Yayasan An-Nizariyyah Bogor). Ustdz Ir. H. Suswono, MM juga mengusulkan kepada kedua waqif tersebut untuk secara bersamaan membangun Sekolah Dasar Islam Terpadu (SDIT) bersamaan dengan pembangunan masjid. Usulan tersebut disepakati, SDIT dibangun dengan menggunakan dana yang ada, sedangkan masjid dibangun dengan bantuan dari Robithoh 'Alam Islami dan muhsinin lainnya. Di tanah waqaf H.M. Nawir seluas 1111 m2 dan dari dr. Kawasan
Mursidin seluas $1.112 \mathrm{~m} 2$ dibangun bangunan masjid berukuran $20 \mathrm{~m} x$ $20 \mathrm{~m}$ dengan dana bantuan dari Robithoh 'Alam Islami. Di tanah ini juga dibangun sebuah gedung sekolah, 2 lantai 6 lokal dengan dana yang ada saat itu. Pada tahun 1997, yayasan mendapat mandat untuk mengelola sejumlah siswa SDIT Sholahuddin yang diserahkan oleh yayasan Annizariyah. Seiring dengan kepercayaan orang tua yang membantu memberikan wakaf mereka, hingga 2012, berkembang pesat dengan luas tanah sekitar $13.386 \mathrm{~m} 2$ dan 7 unit bangunan di atasnya.

Kegiatan yayasannya masih lebih dominan di bidang Pendidikan, sedangkan untuk dakwah, kegiatan sosial dan ekonomi masih di tingkat awal. Dalam perkembangannya, kegiatan pendidikan yang dimulai dari 5 kelas dasar (serah terima kelas 2 6 dari SDIT Sholahuddin), pada tahun 1998 berdiri TKIT Ummul Quro, pada tahun 2002 mendirikan SMPIT Ummul Quro, 2005 lahir Ma'had Mu'alimil Qur ' sebuah (MMQ), yang diberi nama Al-Quran Teachers Training (DGPQ), untuk menamatkan guru Al-Qur'an, ke institusi dan institusi lain di luar Ummul Quro. Para 
siswa berasal dari berbagai profesi dan latar belakang pendidikan, dari ibu rumah tangga hingga karyawan, dari lulusan SMA hingga magister, pada tahun 2011 mendirikan SMAIT. Menjadi institusi pendidikan kelas internasional sudah mulai tumbuh. Hal ini ditandai dengan beberapa prestasi siswa yang diraih di tingkat Internasional baik dalam matematika maupun IImiah Karya IImiah. Juga penerapan Sistem Manajemen ISO menjadi langkah awal menuju arah itu. Mencapai visi menjadi institusi yang berkualitas dan berpengaruh membutuhkan usaha yang terus menerus dan terencana di tahuntahun mendatang.

Kemajuan yang dirasakan cukup baik, berasal dari kepercayaan orang tua dan kerja keras semua elemen yayasan. Oleh karena itu patut disyukuri dan ditindaklanjuti dengan perbaikan manajemen yang memadai. Selain sebagai permintaan, juga untuk memenuhi optimalisasi kegiatan kegiatan dakwah dan sosial. (Tim SDIT: 2017).

SDIT Ummul Quro memiliki visi: Perintis Sekolah Islam Terpadu untuk Generasi Alquran. Beberapa indikator penglihatannya adalah: Kepemimpinan dalam pembinaan pribadi Muslim, yang memimpin dalam kualitas prestasi belajar tahsin dan tahfidz al Qur'an, yang memimpin dalam nilai akademik, yang memimpin pengembangan potensi siswa. Sedangkan misi SDIT Ummul Quro, yaitu: mewujudkan budaya sekolah yang menjunjung tinggi nilai sekolah, mendorong kesadaran siswa untuk menerapkan nilai-nilai Islam dalam kehidupan sehari-hari, memperkuat proses pembinaan dalam pembentukan orang muslim, menumbuhkan semangat membaca dan menghafal qur'an, membakukan administrasi sekolah yang efektif dan efisien, efektif menerapkan pembelajaran dan bimbingan sehingga setiap siswa mencapai nilai akademis yang optimal dan berkembang secara optimal sesuai potensinya, dan menumbuhkan semangat keunggulan secara intensif kepada semua siswa sekolah.

SDIT Ummul Quro menargetkan sasaran mutu pada tahun ajaran 2016-2017, yaitu: memenuhi 95\% standar pendidikan nasional, yaitu; isi, proses, penilaian, manajemen dan kompetensi lulusan, memenuhi standar kualitas SIT $80 \% 5$, standar pengajaran kekuatan 100\% 
Pendas : Jurnal IImiah Pendidikan Dasar, ISSN Cetak : 2477-2143 ISSN Online : 2548-6950 Volume II Nomor 2, Desember 2017

koordinator tingkat, memenuhi kualitas lulusan 90\%, memenuhi panduan ajaran Islam $25 \%$ dari tahun 4- 6 nomor kelas kelas, memenuhi tahfidzul quran $100 \%$ juz 30 dan $1 / 4$ juz 29, lulus ujian 100\% sekolah dengan nilai rata-rata kelas 8,0, skor kelas siswa terendah 6,5 dan skor terendah 3,5, diterima di SMA 100\% dianugerahi medali emas di kejuaraan di tingkat kota dan kabupaten Bogor, yang mendapat penghargaan 3 besar di tingkat provinsi Jawa Barat, meraih 3 besar di kejuaraan nasional, mendapatkan medali di kejuaraan internasional. (Tim SDIT: 2017).

SDIT Ummul Quro menjamin kualitas peserta didik memiliki aqidah yang lurus, melakukan ibadah yang benar, berkepribadian matang dan berakhlak mulia, menjadi pribadi yang bersungguh-sungguh, disiplin dan mampu mengendalikan diri, memiliki kemampuan membaca, menghafal, dan memahami al Qur'an dengan baik, memiliki keterampilan hidup (life skill). Di samping itu SDIT menyelenggarakan program Penguatan Pendidikan Karakter (PPK), yaitu: Sopan santun, bersih dan rapih, shalat dengan kesadaran, birrul walidain, disiplin, jujur, semangat tilawah dan menghafal al quran, serta pembelajar.

Sopan Santun

Bersih dan Rapih

Shalat dengan Kesadaran

birrul walidain

disiplin

Jujur

Membaca dan Menghafal Qur'an

Pembelajar

Gambar Karakter Ummul Quro

\section{E. Kesimpulan}

Penelitian terkait Dinamika Pendidikan Dasar Islam Unggulan di Jawa Barat ini mengungkapkan bahwa Jaringan Sekolah Islam Terpadu memiliki standar mutu kekhasan Sekolah Islam Terpadu yang terdiri dari sebelas (11) standar yaitu; (1) Standar Pendidik dan Ketenagapendidikan, (2) Standar Sarana dan Prasarana, (3). Standar Pembiayaan, (4) Standar Kurikulum, (5) Standar Pengelolaan, (6) Standar Kerjasama, (7) Standar Proses, (8) Standar Penilaian, (9) Standar Pembinaan, (10) Standar Pendidikan Agama Islam, dan (11) Standar Kompetensi Lulusan. Selain standar mutu, Jaringan Sekolah Islam Terpadu mengembangkan 10 
karakter, yaitu; (1) Salimul Aqidah, (2) Shohihul ibadah, (3) Matinul Khuluq, (4) Qodirun 'alal Kasbi, (5) Mutsaqoful Fikri, (6) Qowiyyul Jismi, (7) Mujahadah Lin Nafsi,

Munadzom fi Syu'nihi, (9) Haristun alal Waqti,(10) Nafiun Lighoirihi. Selain mengacu kepada standar mutu dan pengembangan karakter tersebut, Sekolah Dasar Islam Terpadu (SDIT) Nurul Fikri Depok mengembangkan karakter SMART NF yakni Sholeh, Muslih, cerdAs, mandiRi dan Terampil. Sekolah Dasar Islam Terpadu (SDIT) Ummul Quro Bogor menguatkan karakter; sopan santun, bersih dan rapih, shalat dengan kesadaran, birrul walidain, disiplin, jujur, semangat tilawah dan menghafal al Quran, pembelajar. Hasil penelitian tersebut dapat menjadi bahan informasi, pertimbangan maupun implementasi bagi para praktisi pendidikan, pemangku kebijakan, peneliti maupun masyarakat secara umum.

\section{DAFTAR PUSTAKA}

Abdat, Nadia Ja'far \& Lidia Fuji Rahayu, (2015) "Konsep Pendidikan Islam Menurut Ahmad Tafsir". Jurnal Fikrah;
Pendidikan Agama Islam. ISSN 2085-4404 Edisi Juni Vol. 7 No. 1

Alaydroes, et al, (2014) Standar Mutu Kekhasan Sekolah Islam Terpadu, Depok: Jaringan Sekolah Islam terpadu,

Anwar, Muhammad Emnis, (2014) "Menelusuri Kebijakan Pendidikan Islam di Indonesia", Jurnal Edukasi Islami: Jurnal Pendidikan Islam ISSN: 22528970 Edisi Januari Vol. 03, No 05

Dahlan, R, Muhammad, (2015) "Membangun Manusia Berkualitas Melalui Pendidikan", Jurnal Fikrah; Pendidikan Agama Islam. ISSN 2085-4404 Edisi Juni Vol. 8 No. 1

https://jsit-

indonesia.com/2017/08/02/ketu a-jsit-baru-menyapa-kita/ diakses tanggal 4 september 9:50)

Sangit. (2011). Analisis Data Kualitatif. \{online\}. Http//:sangit26.blogspot.com. (diakses 5 April 2015) 
Tafsir, Ahmad, (2013) IImu Pendidikan Islam, Bandung: PT Remaja Rosdakarya,

Tim Bidang Pendidikan, (2016) Implementasi SMART SDIT Nurul Fikri, Depok: Yayasan Nurul Fikri

Tim Bidang Pendidikan, (2016) Panduan Pelaksanaan SMART SDIT Nurul Fikri, Depok: Yayasan Nurul Fikri

Tim SDIT, (2017) It's Me; Buku Panduan dan Budaya Sekolah, Bogor: SDIT Ummul Quro

Tim SDIT, (2017), Sosialisasi Kegiatan Sekolah Tahun pelajaran 2017/2018, Bogor: SDIT Ummul Quro 